\title{
En el laberinto carcelario de Ciges Aparicio
}

\author{
SYLVIA TRUXA
}

Universidad de Padua

Manuel Ciges Aparicio ', el más importante de los precursores inmediatos de la novela social de la Segunda República, es conocido como escritor del primer tercio del siglo XX. Sin embargo, ya a finales del siglo pasado despertó gran interés en el público con las memorias de sus dos años de cautiverio, acusado de traición, en el Castillo de La Cabaña, el fuerte de La Habana.

Tanto éxito tuvo este relato que, con algunas modificaciones, logró ser publicado cuatro veces: la primera como folletín, aparecido bajo el título «Impresiones de La Cabaña» entre el 27 de agosto de 1899 y el 4 de marzo de 1900 en el semanario radical Vida Nueva (donde escribían también «Azorín», Unamuno y Maeztu); la segunda vez en El País, entre el 9 de marzo y el 7 de septiembre de $1903^{2}$. Esta segunda

1 Nacido en 1873 en Enguera, Valencia. Después de una carrera brillante como novelista y periodista, con la Segunda República ingresa en la administración como gobernador civil, primero de Baleares, luego de Santander y, finalmente, de Ávila, donde muere fusilado por los franquistas en julio de 1936. Estuvo casado con Consuelo Martínez Ruiz, hermana de «Azorín». En relación a sus cargos de gobernador civil en Baleares y Santander, véanse los documentos conservados en el Archivo Histórico Nacional, Sección Guerra Civil, en Salamanca; referencias: P.S. Madrid, leg. 2964, t. 14, exped. 11, carp. 328; P.S. Madrid, leg. 3186, t.2, exped. 2, carp. 396; Santander, Serie D, exped. 69, fol. 14,. carp. 19.

2 Es Jesús Arribas, en el estudio hasta ahora más completo del autor levantino, Ciges Aparicio: la narrativa de testimonio y denuncia, Madrid, Ed. Novecientos, 1984, pág. 22, quien por primera vez llama la atención sobre la versión que ofrece EI País, 
versión es casi idéntica ${ }^{3}$ a la que aparece en forma de libro en el mismo año 1903, titulada Del cautiverio ${ }^{4}$. En el año 1930, finalmente, la casa editorial «España», dirigida por Azaña y Araquistain, publica este texto por cuarta vez.

Naturalmente, los estudiosos de Ciges han prestado mucha atención a esta obra, que en su día suscitó tanto entusiasmo y coinciden plenamente en que el motivo de la acusación de traición, que provocó el encarcelamiento del joven sargento Ciges, residiría en la publicación de algunos artículos suyos contra Valeriano Weyler, general en jefe de las tropas españolas en Cuba durante los años 1896 y 1897. Tres testimonios tempranos producirían esta creencia; el primero es una nota biográfica, publicada por Vida Nueva al presentar la figura de Ciges:

Alma noble, enemigo de la injusticia y de la brutalidad [...], escribió una inspirada crónica que envió a $L$ 'Intransigeant de París. Rochefort publicó la crónica de Ciges Aparicio, y apenas llegaron algunos números del batallador periódico francés a La Habana y el general Weyler la leyó, mandó detener y sumariar al osado, con propósito de fusilarle ${ }^{5}$.

La segunda indicación contemporánea proviene del mismo Ciges, que en una escena de Del cautiverio representa su interrogatorio por el juez de instrucción en éstos términos:

-[...] Se le acusa del delito de traición. [...] ¿Reconoce usted este artículo? -Es mío.

- ¿Y cómo ha osado usted escribirlo? [...] Ahí hay graves ofensas para el Capitán General, y usted es un militar que no puede permitirse juzgar... ${ }^{6}$.

Tres años más tarde, en otro libro suyo de memorias noveladas, Ciges vuelve a mencionar sus crónicas publicadas por L'Intransigeant (para ser precisos: habla de una ya publicada y de otra que estaba escribiendo cuando lo detuvieron) ${ }^{7}$.

si bien da erróneamente la fecha inicial del 21-III.

3 Sólo se suprime el último párrafo; ver Arribas, ob. cit., págs. 22 y sigs.

4 Madrid, Ed. Moderna, 1903. Para un estudio detallado de las diferencias entre la primera y las últimas versiones véase Sylvia Truxa, «Texto y contexto de Del cautiverio por Manuel Ciges Aparicio", Iberoamericana (Frankfurt / Main), n. ${ }^{\circ} 22 / 23$, 1984, págs. 48-62.

5 «Ciges Aparicio», Vida Nueva, n. ${ }^{\circ}$ 83, 7-I-1900, pág. 1.

6 Manuel Ciges Aparicio, Del cautiverio, Madrid, Ed. Moderna, 1903, págs. 86 y sig.

7 Manuel Ciges Aparicio, Del cuartel y de la guerra, Madrid, Lib. F. Beltrán, s. a., (1906), pág. 420. 
Menos por dudar de un hecho tan conocido que para poder leer, por fin, estos textos de tan graves consecuencias que todos los investigadores de Ciges mencionan y que nadie cita nunca en concreto, consulté $L$ 'Intransigeant. Ciges no suele dar las fechas o indicaciones necesarias para una reconstrucción cronológica exacta de su estancia en Cuba. Por eso era preciso mirar el periódico parisiense desde el 1-I-1896 al 29-II-1897 ${ }^{8}$. Pero no aparece nada firmado por Ciges, ni siquierá referencia alguna a él. El periódico da numerosas informaciones sobre la guerra de Cuba, muchas de las cuales proporcionadas por el Comité Cuba Libre y su promotor Betances; otras están firmadas por «Cosmo» (pseudónimo del anarquista Carlo Malato), y muchas son anónimas. Aun suponiendo que alguna de estas últimas, brevísimas en general y no dirigidas específicamente contra Weyler, provenga de la pluma de Ciges, habría que preguntarse cómo el general descubrió al autor tras el anonimato.

A fin de excluir olvidos y confusiones, se miraron también La República cubana, periódico del Comité Cuba Libre publicado en París, y Le Journal, diario menos pro-independentista pero mencionado por Ciges como destinatario de las crónicas de su compañero, el soldado Juan Vives ${ }^{9}$. Mas aquí tampoco aparece nada firmado por Ciges Aparicio, y por tanto no se resuelve el enigma: ¿cuándo y dónde publicó Ciges su crónica y cómo se enteró Weyler?

Para tratar de aclarar tanto misterio cabía la posibilidad de investigar la biografía de Manuel Ciges, mediante los datos referentes a su carrera militar. En efecto, a pesar de ser conocido posteriormente como escritor de tendencia antimilitarista, en un momento dado de su vida optó por la profesión de las armas. Él mismo confiesa en un «Memento auto-bio-bibliográfico»:

Luego estudié algunos años... Después surge un conflicto terrible de esos que

8 Se escogió la fecha inicial porque Vida Nueva 83, en su citada presentación del escritor levantino, informa de que éste llegó a Cuba antes que el General Weyler, quien arribó a principios de febrero de 1896 (volveremos sobre ello más abajo), y porque Ciges, en Del cuartel y de la guerra, ob. cit., págs. 287 y 295, insinúa haber escrito contra Weyler ya antes de llegar a la isla. La fecha final la determiné apoyándome en las indicaciones algo borrosas de Ciges mismo acerca de su indulto, que le fue otorgado, según él, en verano de 1898, después de 28 meses de prisión. Por lo tanto, el artículo debería de haber aparecido a más tardar en febrero del año 1897.

9 En ob. cit., pág. 306. 
jamás revela el hombre [...]. Para eludir aquel conflicto a cuyo término sólo veía el presidio y el cementerio, caí en el cuartel ${ }^{10}$.

Tras ingresar en el ejército en el año 1893, en breve tiempo nuestro autor llegó a ser sargento y hasta sustituyó en el mando a un teniente, como se desprende de su obra Del cuartel y de la guerra ${ }^{11}$. Hasta mediados de los años 90 opina que el ejército tiene una función legítima en la sociedad de su tiempo, la de defender la patria contra agresiones externas ${ }^{12}$, y sus primeras críticas de las fuerzas armadas parecen a menudo las de un militar profesional serio y con ideales contra la ineficacia, corrupción y brutalidad de sus superiores -y también de algunos inferiores- que no actúan en defensa de la patria sino por motivos y fines inaceptables ${ }^{13}$.

Todo esto podría muy bien inducir a pensar que, en su juventud, había escogido la carrera militar, cambiando su rumbo profesional después de su regreso de Cuba, por más de una causa. Pero resulta que no aparece ninguna hoja de servicios (documento inexcusable de todo militar profesional) de Ciges Aparicio en el Archivo General Militar de Segovia, ni en el del Cuartel General del Ejército en Madrid. Por lo tanto podemos dar crédito a otras afirmaciones, de Ciges, implícitas éstas, según las cuales entró de recluta ${ }^{14}$. Es, en este caso, de suponer que en el citado «Memento...» se refiere a haber ido voluntario al ejército, 0 , aún más probablemente, a no haberse redimido del servicio militar en el momento de ser sorteado -como lo hacían tantos otros que disponían de los recursos necesarios-, siguiendo luego una carrera del tipo que hoy se denominaría «oficiales de la escala de complemento».

Aunque no consta, pues, documento sobre una carrera de Ciges Aparicio como militar profesional, sí se conserva en el Archivo General Militar de Segovia un expediente personal suyo. Éste se limita a sus

10 Manuel Ciges Aparicio, «Memento auto-bio-bibliográfico» en: Andrés González Blanco, Los contemporáneos. Apuntes para una historia de la literatura hispanoamericana a principios del s. XX. Primera serie, París, Garnier, s.a. (Colofón de 1906), pág. 208.

11 M. Ciges Aparicio, Del cuartel y de la guerra, pág. 307.

12 M. Ciges Aparicio. «Pro autonomía», El País (Madrid), 1-I-1896, pág. 1.

Cfr., por ejemplo, Del cuartel y de la guerra, págs. 304-307, y «Pro autonomía».

Por ejemplo: «ante una puerta nos detenemos los reclutas», Del cuartel y de la guerra, pág. 7. 
problemas con la justicia militar en Cuba. Cubre el tiempo que va desde los primeros días de 1897 hasta marzo de 1899, ofreciendo, además, referencias sobre hechos que se produjeron entre agosto y diciembre de 1896. Este expediente, que se compone de unas 130 hojas, por fin arroja luz sobre las causas y la cronología del encarcelamiento y del proceso del futuro escritor. Consiste en:

A. Un conjunto de cartas, volantes y telegramas referentes a Manuel Ciges Aparicio y otras dos personas que fueron acusadas en el mismo proceso por traición, a saber, al soldado Juan Vives, perteneciente al Batallón de Cazadores de Barcelona, como el propio Ciges, y al cura párroco de Ciego de Ávila (Cuba), Miguel Franzón.

B. Dos dossiers en que se registran puntualmente los trámites de procedimiento del proceso. Nos interesa sólo el segundo de estos dossiers, el del Estado Mayor, Sección 5 (37 hojas), ya que el primero ${ }^{15}$ no muestra ninguna relación entre la cubierta, que se refiere a Ciges, Vives y «Frans» [sic], y las dos páginas del contenido.

C. Finalmente, el expediente contiene una carta autógrafa de $\mathrm{Ci}$ ges, pidiendo una mayor ración de pan al Gobernador de La Cabaña, y dos copias de cartas del mismo autor, una a Juan Vives en Ciego de Ávila, la otra a Henry Rochefort, director de L'Intransigeant en París.

Digámoslo ya de una vez: la sorpresa mayor que proporciona el expediente estriba en que, con toda probabilidad, y a pesar de lo que creyera y dijera el propio Ciges, no llegó a publicarse nunca ningún artículo suyo en $L$ 'Intransigeant. En efecto, la carta, o más bien crónica, firmada con nombre y apellido, que envió a Rochefort, fue interceptada por motivos que tienen que ver con Ciges sólo de manera indirecta: Juan Vives, su compañero, corresponsal y enlace con $L$ 'Intransigeant, se hallaba sometido a vigilancia por la justicia militar a causa de haberse alistado en el ejército español con nombre e identidad falsas; de hecho, se llamaba Mario Vittorio Divizzia, y era de nacionalidad italiana.

Vives Divizzia fue detenido el 31 de diciembre de 1896 en Ciego de Avila, provincia de Camagüey. La mencionada carta de Ciges a Vives, con fecha del 14 de diciembre de 1896, lleva la firma «Manuel Pancracio». Es de suponer que se trata de un pseudónimo de Ciges, ya que

15 Del Cuerpo del Ejército de Occidente, E. M. Sección 4a, con anotaciones entre el 6-IX y el 12-X de 1896. 
en el escrito Vives aparece claramente como enlace entre «Manuel» «Henry» (Rochefort), para quien «Manuel Pancracio» dice haber redactado una crónica. También parece Ciges ser el autor de la carta porque «Manuel Pancracio» se halla en la provincia de Pinar del Río, justamente donde estaba nuestro escritor durante el invierno de 1896, y donde fue detenido. Para mayor prueba contiene el expediente un cablegrama cifrado del General Bazán (Ciego de Ávila) al General Ahumada (La Habana); lo cito en parte: «Autor carta sargento octava compañía Barcelona Miguel Ciger [sic] Aparicio.» Este cablegrama, con el que se inicia la persecución de Ciges por la justicia castrense, no está fechado, pero se menciona al «soldado Juan Vivé [sic] detenido; nombre verdadero Mario Víctor Hodivizia [sic], origen italiano (...)». Habiendo sido detenido Vives Divizzia el 31 de diciembre de 1896, y no constatando aún mención alguna de la detención de Ciges en el cable, éste tiene que haber sido transmitido entre el primero y el seis de enero de 1897, fecha en que es arrestado Ciges Aparicio.

La carta de éste a Vives habría puesto a las autoridades sobre la pista de Ciges, razón por la cual lo vigilaron e interceptaron el segundo escrito cigiano en el dossier, la crónica, que termina de la siguiente manera: «(M.C.) = Macía». Macía es, según las prácticas de cualquier sector administrativo español de la época, el apellido del copista, y M. C. son las iniciales de la firma al pie del documento, con toda probabilidad la de Manuel Ciges. La crónica no está fechada, pero debe de ser de las últimas semanas de diciembre de 1896 o de los primeros días del año 1897, porque contiene referencias exactas a la muerte de Antonio Maceo, acontecida el 7 de diciembre de 1896. Y no puede haber sido escrita después del 5 de enero de 1897, como ahora se verá.

Data del 6 de enero de 1897, de las 10.40 de la mañana, aquel famoso telegrama del General Weyler, el «papel azul» del cual habla Ciges ya en la primera versión de sus memorias de la cárcel. Lo ve sin poder leerlo, y jamás llega a saber el contenido ni el remitente ${ }^{16}$. A partir de este momento se desencadenan, con suma eficacia y rapidez, las complicadas medidas administrativas para llevar a Ciges desde el pueblo de Artemisa (Pinar del Río), el lugar de su detención inicial, a La Habana, cruzando la línea fortificada de la trocha, que atravesaba la isla entera. id., Del cautiverio, pág. 32 . 
Ciges ingresa en la Cabaña, como preso incomunicado, el 7 de enero de 1897. Y esto, por lo visto, se debía al hecho de ser sospechoso de tener relaciones con los independentistas ${ }^{17}$, y no al de haber publicado nada en periódicos parisienses. El dossier que contiene el trámite del procedimiento de la justicia castrense muestra que los mismos militares, aún un año después de la detención de Ciges, sabían sólo indirectamente de un eventual artículo; en anotación del 17 de enero de 1898 se lee: «[...] Según cartas de Siges (sic) [...] que se han recogido, resulta que éste publicó en aquel diario paricience (sic) una correspondencia cuyo contexto no se conoce sobre la situación de este País (sic)».

La utilidad de una reconstrucción cronológica es evidente si tenemos en cuenta que todo resulta más que borroso, no sólo para los estudiosos que se ocupan de Ciges hoy día, sino hasta para los contemporáneos del autor. En efecto, en la citada presentación de Ciges por Vida Nueva se lee: «[Ciges quedó] olvidado en los calabozos de La Cabaña mientras el caudillo [Weyler] [...] perseguía con cuarenta batallones nada menos al cabecilla Maceo que pasó tranquilamente la Trocha (sic)»; o sea, que Ciges habría estado preso en La Habana ya desde hace mucho tiempo antes de la muerte de Maceo, mientras, en realidad, en aquel momento Ciges Aparicio aún no estaba ni siquiera detenido.

Además, según Vida Nueva, «Ciges Aparicio se encontraba en Cuba cuando desembarcó el general Weyler en la isla y comenzó allí el reinado de terror que Cánovas aconsejaba»; es decir, el escritor levantino habría llegado antes de Febrero 1896. Varios de los documentos conservados en Segovia, en cambio, informan que Ciges se embarcó para La Habana sólo en agosto de 1896.

Pasando ahora al plano literario, el conocimiento de la cronología nos induce a pensar que es ficción el relato de ciertas aventuras conmovedoras al principio de la obra sobre la prisión cubana de Ciges. Son escenas muy halagadoras para nuestro sargento valenciano, que le muestran como oficial querido entrañablemente por sus subordinados. Estas escenas, según el escritor, se producen durante las «48 horas» tras su detención en Artemisa. De hecho, se mencionan sólo en Del cautiverio de 1903, (págs. 19 y sigs.), versión de las memorias mucho más dramá-

17 «Ciges Aparicio de quien se sospechó que estuviese en relación con los rebeldes». Anotación del 17-I-1898 en el dossier de trámites. 
tica y extensa que las «Impresiones» de 1899. En realidad, Ciges no pasó más que una tarde y una noche en su prisión provisional de Artemisa, estando, además, completamente incomunicado.

Vamos a puntualizar ahora la cronología y las fechas de los acontecimientos, basándonos en los materiales contenidos en el expediente de Segovia, con el fin de desvelar posibles misterios y aclarar las ambigüedades producidas por el relato ucrónico del escritor levantino. Éste, si bien nos habla de sus «veintiocho meses» de prisión ${ }^{18}$, y hasta los subdivide (no pocas veces erróneamente), no los sitúa en el tiempo, además de localizarlos mal en el espacio, ya que durante los últimos cinco meses y medio se hallaba en Barcelona, y no en Cuba. Los documentos descubiertos en Segovia por una parte proporcionan datos completamente ignotos hasta ahora, por otra invalidan muchas informaciones avanzadas por la crítica o el propio Ciges.

Todo empieza el 16 de agosto de 1896 con el embarque en Barcelona, para La Habana, de Juan Vives alias Mario Divizzia ${ }^{19}$ y de Manuel Ciges Aparicio. Después de la micro-cronología, ya expuesta más arriba, de la detención del último en Artemisa el 6 de enero de 1897 y de su ingreso el día siguiente en La Cabaña, Ciges es sometido a los primeros interrogatorios por el juez instructor Villares el 10 y el 12 de enero de 1897. Pero sólo el 28 del mismo mes se abre el dossier de trámites. (Es de suponer que todo lo anterior se halle en la documentación de la causa propiamente dicha, que se perdió; más abajo se tratará de su destino).

Con todo esto, como se desprende de una carta que se halla entre los documentos conservados en el expediente personal, el 29 de enero el Jefe Representante del batallón de Ciges seguía ignorando los motivos del arresto e incomunicación del joven sargento. De hecho, hay que esperar hasta el 6 de septiembre de 1897 para encontrar el primer testimonio de la acusación del delito de traición contra Vives y Ciges en el expediente.

18 «Recuerdos de veintiocho meses» es el subtítulo de las «Impresiones de La Cabaña» en Vida Nueva.

19 Debo rectificarme a mí misma: en mi citado artículo, pág. 52, supongo por varios motivos que Vives es un personaje ficiticio. Ya se ve que me equivoqué -es personaje histórico, aunque mucho más novelesco, más inverosímil que muchos entes de ficción. 
El 17 de enero de 1898, después de algunas intervenciones del embajador y del cónsul italianos en Cuba, el juez sobresee la acusación por traición contra Vives, por ser anulado el ingreso de éste, extranjero, en el ejército español. El 20 de enero, Vives es embarcado, bajo estricta vigilancia, para España, donde será procesado por falsedad de nombre y nacionalidad. Además sigue siendo sospechoso de relaciones con anarquistas. (A esta sospecha, según anotaciones del 17 de enero de 1898 en el dossier de trámites, había contribuido Ciges Aparicio). El tercer acusado en el proceso, el cura Franzón, había logrado la libertad provisional ya el 21 de abril del año 97, «por aparecer de lo actuado que no [tenía] responsabilidad alguna» ${ }^{20}$. (No le habría sido inútil el besamanos que el obispo de La Habana mandó a Weyler en su favor, este delicado billetito de tenue color que está cuidadosamente guardado entre los austeros documentos militares del expediente personal de Ciges). De esta manera, ya no quedaba otro acusado que el futuro novelista.

Se reúne el Consejo de Guerra para juzgarle el 22 de agosto de 1898 , después de por lo menos otro interrogatorio, que tiene lugar el 14 de agosto, y de algunos trámites entre el juez instructor y el defensor de Ciges, cierto teniente Foradellas, quien pide pruebas al juez el 28 de mayo del 98. El Consejo de Guerra falla juicio el mismo 22 de agosto: el delito de Ciges, al fin y al cabo, no consiste en traición, sino en injuria al ejército, que según el art. 258 del código militar entonces en vigor, se puede castigar con 28 meses y un día de prisión correccional, siéndole abonado a Ciges la mitad de la prisión preventiva sufrida, o sea, nueve meses y tres semanas.

El 10 de diciembre de 1898, el procesado, que aún no está enterado del juicio y por lo tanto debe estar todavía temiendo su fusilamiento por supuesto traidor, es embarcado hacia Barcelona en el contexto de la retirada de las tropas españolas de Cuba. Sólo cuando se halla ya en alta mar, el 14 de diciembre, el expediente de su causa pasa al juez Valerio Todo Diego para notificación de la sentencia...

20 Anotación del 21-IV-1897 en el dossier de trámites. Resulta que Vives se había conquistado la simpatía del párroco, pidiéndole instrucción religiosa con el fin de prepararse para su bautismo. Franzón, llevado por el entusiasmo de poder salvar un alma, le enseñó, le prestó dinero y aceptó recibir en su domicilio la correspondencia comprometedora de Vives. 
Y aquí se pierde toda huella de este documento. Tras la petición de indulto de Ciges, el Capitán General de Cataluña, con fecha de 26 de febrero de 1899, pide al Archivo General Militar de Segovia la documentación de la causa. El 18 de marzo el jefe del Archivo responde que el último «detentador» [sic] conocido de la totalidad de los documentos era el juez Todo Diego. La búsqueda del expediente produce un carteo intenso entre Segovia, Barcelona y el Ministerio de la Guerra en Madrid, al parecer sin éxito alguno. Estas cartas son los últimos documentos que contiene el expediente personal conservado en Segovia. Sobre los acontecimientos sucesivos no tenemos más testimonio que el del propio Ciges, el cual, al final de Del cautiverio, dice que fue indultado a los 28.meses de prisión; es decir, según nuestra cuenta, a principios de mayo de 1899.

El incipiente novelista es así paradigma de aquellos españoles encarcelados por reales o supuestos vínculos con los independentistas, cuyo indulto tardó mucho más que el de los mismos cubanos ${ }^{21}$.

Como se ve fácilmente, el indulto tenía poco efecto práctico: entre Cuba y Barcelona, Ciges pasó en la cárcel la totalidad de los veintiocho meses a los cuales había sido condenado con motivo de aquella infeliz crónica que aquí se publica por primera vez.

Esta crónica constituye uno de los primeros testimonios seguros del periodismo comprometido de Ciges Aparicio; si no me equivoco, es, por lo que se sabe hasta hoy, el segundo escrito de este tipo después del citado artículo «Pro autonomía» en El País del 1-I-1896, firmado con el pseudónimo «Escipión». Por su voluntad de no solamente relatar los hechos, sino de interpretarlos, de aclarar el fondo político de la acción bélica -en gran parte vivida en primera persona por el autorla crónica, si hubiese llegado a sus destinatarios, los lectores franceses, hubiera sido una contribución considerable para una información mejor y más analítica de la opinión pública contemporánea de aquella guerra tan «desastrosa» para España. Y no sólo de la opinión pública francesa, sino de la europea en general, ya que L'Intransigeant no era desconocido en los círculos republicanos de otros países.

21 Sobre este fenómeno en la guerra de Cuba, cfr. Carlos Serrano, «La colonie pénitenciaire; rebelles, anarchistes, ñáñigos dans les pénitenciers espagnols 1885 - 1899», Mélanges amèricanistes en hommage à Paul Verdevoye, Paris, Éditions Hispaniques, 1985, pp. 79-92. 
En lo que concierne al autor, el texto aquí reproducido muestra dónde y cómo nace la posterior actitud antimilitar de Ciges. Esta última, en efecto, no es fruto del resentimiento de un hombre que sufrió larga y durísima prisión, sino que tiene razones técnicas: Weyler, visto como militar inútilmente cruel $\mathrm{y}$, para colmo, incapaz, no ofrecía estímulos de identificación a aquel espíritu ético y, digamos, de correcta profesionalidad militar, que tenía el joven Ciges. Éste, en cambio, respeta y a veces hasta admira las dotes políticas y militares de los hombres que, como sargento español, debe combatir, es decir, los independentistas. Son, entre otros motivos, estas cualidades de sus adversarios las que llevan a nuestro autor muy cerca de la identificación con la causa patriótica cubana.

En el nivel literario, la crónica malograda es un ejemplo temprano del estilo sencillo pero pulido, levemente irónico, que distingue las últimas obras del levantino, en particular la novela Los caimanes (1931). Se trata de un estilo que contrasta con el tono enfático y aun hinchado de los demás textos escritos poco después del regreso de Ciges a España, como las memorias de la prisión y la novela El vicario (1905) ${ }^{22}$.

Fue, desde luego, una gran suerte no sólo para Ciges Aparicio, sino también para las letras españolas, el que la justicia castrense tomara por carta personal aquel texto destinado a la prensa, del cual el General Bazán, en Ciego de Ávila, escribe en estos términos: «una casualidad ha hecho que caigan en nuestro poder estas dos cartas que se complementan ${ }^{23}$. Este error judicial salvó la vida del joven acusado, quien, en otras circunstancias, hubiera sido juzgado, como mínimo, como «reo de delito contra la Seguridad de la Patria» ${ }^{24}$.

No hay unanimidad de opinión sobre el estilo de Ciges Aparicio. Muchos contemporáneos suyos alaban su escritura con estusiasmo, entre ellos Valle Inclán, «Azorín» y Cansinos Assens. Tampoco le faltan admiradores en nuestros días, por ejemplo Víctor Fuentes y Eugenio de Nora. Pero hay otras voces (P. Gil Casado, Andrés Amorós) que, aun apreciando mucho su valor testimonial y su capacidad de construcción artística, encuentran el estilo de Ciges desagradablemente retórico. Hemos estudiado el problema — que depende mucho de las transformaciones estilísticas que se pueden observar en la obra de nuestro autor- en el citado artículo en Iberoromania, págs. 49 y sig.

Se trata de la carta sin fecha que acompaña el envío, desde Ciego de Ávila a La Habana, de las copias de la crónica dirigida a Henry Rochefort y de la carta firmada «Manuel Pancracio», dirigida a Vives-Divizzia.

24 Poco después de llegar a Cuba, Weyler promulgó un bando que cito en parte: «Hago saber [...] Quedan sujetos a la jurisdicción de guerra los que se hallen compren- 
Agradezco al General Armando Marcante útiles indicaciones sobre algunos aspectos del funcionamiento del ejército. También quedo agradecida a la dirección y al personal del Archivo General Militar de Segovia por las facilidades que me ofrecieron.

\author{
-Copia del Sobre- \\ (Via Tampa) Francia \\ M. Henry Rochefort \\ De L'Intransigeant \\ Paris
}

\title{
- Copia de la Carta-
}

Desde la Isla de Cuba = La circunstancia de ser la Provincia de Pinar del Río uno de los principales focos de la insurrección cubana, tanto por la del terreno como por haber fijado en ella su campamento Maceo, es causa de que todo el mundo haya prestado durante mucho tiempo singular atención en los sucesos de que ha sido teatro. Natural es por lo tanto que el interés subiese de pronto al tenerse noticias de que el General Weyler iba á dirijir [sic] personalmente las operaciones contra el cabecilla de occidente.

El estado ruinoso de España, la complicación de sus asuntos en el archipiélago filipino, Puerto Rico y las kábilas fronterizas de Melilla, juntamente con el temor de un rompimiento que la podría ser funesto con los Estados de la Unión, determinaron al Gobierno de Madrid a instar al Capitán General de Cuba para que intentase terminar en breve plazo la insurrección. Dicho está, que siendo el cabecilla mulato, sino [sic por si no] el más prestigioso, sí el mas temido enemigo de España, contra él había preferentemente que dirijir [sic] las armas. Un ejército formidable, si se tiene en cuenta las fuerzas relativamente poco numerosas del caudillo separatista, ha cruzado las montañas en toda su extensión; ¿Ha conseguido el General Weyler el fin que se proponía de ahogar la insurrección en las lomas? = La prensa vocinglera,

didos, entre otros casos marcados por la ley, en los siguientes: $1 .^{\circ}$ ) Que intenten o propalen, por cualquier medio, noticias o especies directa o indirectamente favorables a la rebelión, debiendo considerárselos como reos de delito contra la Seguridad de la Patria.» (Bando del 16.2.1986). Y, dos meses después: «Ordeno y mando [...]: 3. ${ }^{\circ}$ Queda prohibida la publicación de sueltos, artículos y grabados que directa o indirectamente tiendan a menoscabar el prestigio de la Patria, del Ejército o de las Autoridades, a exagerar las fuerzas y la importancia de la insurrección o a favorecerla de cualquier modo; a producir alarmas infundadas o a excitar las pasiones [...]». Los bandos están citados en Valeriano Weyler, Mi mando en Cuba (10 de febrero 1986 a 31 de octubre 1897). Historia militar y política de la última guerra separatista durante dicho mando, t.I (3 tomos), Madrid, Felipe González Rojas, 1910, págs. 177 y 321 . 
los patriotas cursis, dirán que sí; el buen sentido dice que no. No la táctica ni la estrategia, sino un capricho de la fortuna, la fatalidad si se quiere, es causa de que se haya trocado en triunfo para él (triunfo efímero en puridad) el golpe que le amenazaba triturar; porque no otra cosa que derrotado puede decirse del General en Jefe que deja su despacho de la capital para dirijir [sic] personalmente unas operaciones de importancia suma, tanto por la condición del enemigo, de antemano constreñido dentro de una línea militar de quince mil hombres, como por lo numeroso del ejército perseguidor, y que llegado al teatro de la guerra, donde todo el mundo presume que han de desarrollarse acontecimientos de capital transcendencia para el proceso y pacificación de la isla, sufre la burla de servir de juguete a un enemigo que le hostiliza frecuentemente, como para anunciarle su presencia; pero que al pretender atacarlo desaparece como nube de estío, dejando expedito el camino... un camino que, para mayor burla, para que esta adquiera las proporciones del escarnio, queda sembrado de enfermos víctimas de la fiebre, del hambre y de la fatiga, hasta que la retaguardia se encarga de recojerlos [sic].

La insurrección, con sagaz juicio, ha adoptado desde un principio dos medios de hacer la guerra; no atacar sino cuando el triunfo es casi seguro y producir golpes de verdadero efecto moral. Y hace bien; sería imposible que pudiese de otra suerte vencer a un enemigo que le septuplica en número y tiene la ventaja de la organización y del armamento. Este plan preconcebido ha sido continuado felizmente desde que el General Weyler con más de treinta y cinco mil hombres penetró en las lomas del Pinar. A parte de la acción en que fue herido el General Echagüe, ningún otro fuego ha tenido la más nimia importancia, todo se ha reducido a insignificantes tiroteos. Ahora bien; sumadas las bajas que según los partes oficiales ha tenido la insurrección en el mes que ha operado el General en Jefe, la cifra total no excede de cincuenta, menos aún de las que ha tenido el ejercito español en los diversos fuegos. Pero mientras en la insurrección hace [sic] poca mella las enfermedades, entre los últimos se ha cebado despiadadamente; más del quince por ciento de las tropas que han operado en el mes de noviembre ha ingresado en los hospitales de sangre establecidos en los poblados inmediatos a las montañas. Hase dado el caso de advertir los directores de aquéllos que no era posible la admisión de más enfermos por ser insuficientes para contenerlos. Si ahora se computa en un cinco por ciento, como de antiguo viene haciéndose, el número de defunciones ocasionadas por las enfermedades, fácil será formar concepto del resultado de tan decantadas operaciones.

$\mathrm{Y}$ a pesar de cuanto se ha dicho en contrario, hasta ahora continúa sin extirpar el separatismo en Pinar del Río. ¿Lo conseguirá Weyler? Habiendo faltado a aquel su caudillo no es mucho que lo consiga, arrastrando el General español tan poderoso ejército; pero costará aún tiempo, tanto como al sobrio mambís no le falte el tasajo, la yuca, ni el moniato que puede decirse constituyen casi su alimento. Así lo ha debido comprender Weyler cuando, ya que no enemigos, ha dedicado singular empeño en destruir cuantas reses y plantaciones ha encontrado a su paso desde la trocha hasta el otro lado de las montañas.

Toda la ventaja que hasta hoy ha conseguido el capitán general de la isla en el departamento occidental ha sido, pues, ésta: privar a la insurrección de buena cantidad de comida; y así, paulatinamente podrá desalojar al enemigo de todas sus posiciones. En cambio la fama militar de Weyler ha estado en esta ocasión en un brete. Los golpes de efecto moral con que le amenazaba 
Maceo eran tremebundos. Este cabecilla cañoneando a Artemisa, sin propósito de cruzar la trocha en aquella ocasión, mientras numerosas columnas lo buscaban por las montañas de Quiscán, Rubí, Soroa etcétera, demostraba con hechos contundentes, $o$ que sus perseguidores no eran muy perspicaces, o que al propio valor unía excelente talento militar, quizás ambas cosas a la vez. Por último, valor temerario y talento militar y político en grado eminente rebeló [sic] al abandonar las montañas sin ser notado, cruzar la famosa trocha, siquiera fuese por las aguas de Mariel, e intentar dirijirse [sic], después de concentrar gente, a hacer con la capital de la isla lo que antes había hecho con la capitalidad de la trocha militar, no con intención, como en ésta, de apoderarse de ella, cosa imposible; pero sí de seguro efecto que hubiese demostrado la superioridad de un caudillo y producido, cuando menos, la dimisión del otro.

Mas, desgraciadamente para la causa separatista, cuando los peligros capitales habían sido sorteados, cuando el jefe insurrecto se disponía a dar el golpe de gracia, un encuentro fatal, inesperado, agostó antes de sazonar plan tan vasto. Para mayor desgracia, pero también para menor gloria del vencedor Maceo murió vulgarmente, no como el hijo de Máximo Gómez, suicidandose por no caer, ya herido, en poder del enemigo, sino como obscuro soldado que le sorprende inopinadamente la bala disparada a kilómetro o el machete de vulgar enemigo. iNi el vencedor supo con quien contendía, ni el cadaver fue reconocido hasta bien tarde!

Con la muerte de Antonio Maceo la insurrección ha recibido un duro golpe en la cabeza, no hay que negarlo. El júbilo que los españoles sienten y las alabanzas tributadas a Weyler y Cirujeda, aunque exageradas, son perfectamente explicables; pero el mucho contento puede muy bien torcer el recto juicio, y así sucede a los que auguran que la pacificación de Cuba sólo es obra ya de algunos, muy pocos meses. Lo propio ocurrió cuando acaeció la muerte de otro prestigioso jefe de la insurrección, Martí; y, esto no obstante, después de él es cuando adquirió mayores bríos. Todavía quedan numerosos hombres de suficiente crédito y excelente espíritu militar que peleen con tenacidad por la independencia de Cuba; las partidas que la recorren son muy numerosas, y aún no se ha conseguido la pacificación completa de ningún departamento; prejuzgar cualquier cosa es exponerse a errar. El tiempo resolverá este litigio $=$ (M.C.) $=$ Macía 